\title{
Hospitalists as a staffing innovation: does it impact hospital efficiency?
}

\author{
This article was published in the following Dove Press journal: \\ Innovation and Entrepreneurship in Health \\ 7 January 2015 \\ Number of times this article has been viewed
}

\author{
Josué P Epané \\ Robert Weech-Maldonado ${ }^{2}$ \\ 'Department of Health Care \\ Administration and Policy, University \\ of Nevada, Las Vegas, NV, '2Department \\ of Health Services Administration, \\ University of Alabama at Birmingham, \\ Birmingham, AL, USA
}

Background: The use of "hospitalists", a staffing innovation introduced in the US health care system in the mid-1990s, has grown rapidly in recent years. These hospital-based physicians have been found to be more efficient (reduced length of stay and costs) compared to their nonhospitalist counterparts. However, these studies have generally been conducted on single teaching or pediatric hospitals.

Purpose: This study explored the association between the use of hospitalists and efficiency, as measured by length of stay (LOS), operating costs per inpatient day, and registered nurse (RN) staffing per bed.

Materials and methods: A panel-design regression with hospital and year-fixed effects was conducted among a national sample of medical surgical acute care hospitals operating in the US between 2007 and 2010. Three separate fixed-effect regressions models were used for each of the three dependent variables: LOS, operating costs per inpatient day, and RN staffing per bed.

Results: Our findings indicate that high hospitalist staffing intensity (hospitalist full-time equivalents per 1,000 adjusted inpatient days) is associated with lower LOS, but also higher operating costs and RN staffing per bed.

Conclusion: Hospital managers should consider the potential implications of hospitalist use as an innovation strategy. While hospitals with higher hospitalist staffing intensity may experience lower LOS, this may come at the expense of increased operating costs and RN staffing.

Keywords: hospitalists, staffing innovation, efficiency, costs, RN staffing

\section{Introduction}

The health care industry is quite dynamic, and constantly experiences various types of innovations. Some of these innovations are more successful than others. Electronic health records, patient portals, accountable care organizations, telemedicine, regenerative medicine, and other biomedical innovations are some of the innovations the health care industry has seen in the last decades. The use of "hospitalists" is a staffing innovation that US hospitals started adopting in the mid-1990s. Hospitalists are a group of hospital-based physicians who specialize in the practice of hospital medicine. ${ }^{1,2}$ Hospitalists represent several different specialties, such as cardiology, family practice, gastroenterology, general internal medicine, gynecology, neurology, pediatrics, pulmonology, and surgery; however, general internal medicine accounts for about $75 \%$ of hospitalists. ${ }^{3-5}$ For the past two decades, this staffing strategy has grown rapidly in the US, from fewer than 1000 practicing hospitalists in the mid-1990s ${ }^{6}$ to 40,687 practicing hospitalists in $2012 .{ }^{7}$

Stakeholders in the US hospital industry are increasingly focusing on improving quality of care while reducing costs. This is in part being fueled by the Affordable 
Care Act and the value-based purchasing program, which reward providers who are able to provide high-quality care at lower cost. ${ }^{8}$ As such, hospitals have a growing interest in the use of hospitalists as an innovative staffing strategy that has the potential of increasing efficiency (reduced length of stay [LOS] and lower costs), while achieving similar or better health outcomes. As hospitals are under increasing pressure to provide value-based care, and given the growing use of hospitalists, it is important to determine whether the use of hospitalists results in increased hospital efficiency.

Prior literature has shown that compared to nonhospitalists, hospitalists are more efficient by reducing $\operatorname{LOS}^{9-15}$ and costs, ${ }^{9-12,15}$ while providing similar or better quality (readmissions and mortality rates) ${ }^{15-23}$ and patient satisfaction ${ }^{15,24}$ compared to their nonhospitalist counterparts. However, a few studies have found hospitalists to have no significant reduction in $\operatorname{LOS}^{21,23}$ and/or costs. ${ }^{13,21,23,25,26}$

Most prior studies have been done at the patient level, and have not examined the effect of hospitalist use on hospital-level outcomes. Examining whether the observed patient-level benefits hold at the organizational level can inform policy makers and hospital leadership on the organizational benefits of this innovative staffing strategy. Additionally, most studies to date on hospitalists have been cross-sectional single-hospital studies, generally performed among teaching or pediatric hospitals. To fill this gap in the literature, our longitudinal study aimed to explore the relationship between the use of hospitalists and efficiency, as measured by LOS, operating costs, and registered nurse (RN) staffing per bed using a national sample of US medical surgical acute care hospitals operating in the US between 2007 and 2010.

\section{Conceptual framework}

Agency theory is used to assess the association between hospital use of hospitalists and efficiency. The agency relationship is as old as there have been social interactions between two or more parties (the principal and the agent), one acting on behalf of the other. ${ }^{27}$ Agency theory suggests the establishment of a contract between the principal (hospital), who hires, contracts, and delegates decision-making authority, and the agent (hospitalist), who acts for, on behalf of, or as a representative for the principal. The contractual arrangement helps to guarantee that the agent acts in the best interest of the principal's welfare. The advent of hospitalists has created a shift from the traditional model in the relationship between hospitals and physicians, ie, from two independent ${ }^{28,29}$ and often conflicting ${ }^{30-32}$ entities with misaligned goals and conflict of interest ${ }^{30,33-35}$ to a better-integrated and collaborative partnership between these two entities. This partnership/relationship is now better codified by hospitalist contractual arrangements. ${ }^{36-39}$

Agency theory suggests the establishment of a contract between the principal and the agent, coupled with incentives, as a mechanism to align the agent's goals to that of the principal. ${ }^{40}$ Over the last two decades, there has been a growing trend for physicians' integration/alignment with hospitals, ${ }^{41}$ and the use of hospitalists has increasingly become one such strategy. It is believed that to the extent that hospitals are able to align their goals with those of the hospitalist, they may become more efficient.

As hospitalists spend $80 \%$ or more of their time in the hospitals, they may have increased real-time reaction to clinical data ${ }^{42-44}$ compared to community physicians (nonhospitalists). This may enable hospitalists to provide adequate inpatient care in a timely manner, and may result in earlier discharges without negatively impacting health outcomes. This is supported by prior studies, suggesting that hospitalists are able to reduce LOS compared to nonhospitalists within the same hospital. ${ }^{11,14-16,18}$ We consequently hypothesize that:

- $\mathrm{H}_{1}$ - an increase in hospitalist staffing intensity is associated with lower LOS.

Given that hospitalists spend a considerable amount of time at the bedside, they are able to streamline and better control the process of care, avoiding unnecessary and duplicate services, such as lab tests and other medical procedures. As such, hospitalists can potentially reduce costs of care. Furthermore, as hospitalists reduce LOS, the need for additional support clinical personnel may be reduced, which may in turn reduce RN staffing needs. It is therefore hypothesized that:

- $\mathrm{H}_{2}$ - an increase in hospitalist staffing intensity is associated with lower operating costs, and

- $\mathrm{H}_{3}-$ an increase in hospitalist staffing intensity is associated with lower RN staffing per bed.

\section{Materials and methods Data}

Data sources for this study included the American Hospital Association (AHA) Annual Survey, Area Health Resource File (AHRF), Centers for Medicare and Medicaid Services (CMS) cost reports, and case-mix index (CMI) files. The AHA survey provided demographics, organizational structure, utilization, physician arrangements, and staffing information. ${ }^{45}$ The AHRF data set provided county-level 
information on health facilities, health professions, measures of resource scarcity, economic activity, and socioeconomic and environmental characteristics, such as Medicare managed care penetration, per-capita income, and geographic location. ${ }^{46}$ Medicare cost reports provided financial as well as some utilization information. ${ }^{47}$ The CMS CMI file provided case-mix data for each hospital. Our study was deemed exempt in terms of human subjects by the University of Alabama at Birmingham Institutional Review Board.

The sample for this study consisted of a national sample of medical surgical acute care hospitals operating in the US between 2007 and 2010. After merging all data sets (AHA, AHRF, CMI, and Medicare cost reports), the sample consisted of 18,487 hospital-year observations (4,622 hospitals per year on average). There were 617 duplicate observations that were deleted, which reduced our sample to 16,021 hospital-year observations $(4,005$ hospitals per year on average). There were 367 hospitals that reported using hospitalists, but also reported no or missing full-time equivalent (FTE) hospitalists; these observations were deleted, resulting in a sample of 14,553 hospital-year observations (3,638 hospitals per year on average). After deleting observations with missing dependent variables, our final sample consisted of 14,055 hospital-year observations (3,514 hospitals per year on average). Specialty and long-term-care hospitals were not included in our sample, given their unique operating environment.

\section{Variables}

Table 1 presents definitions and data sources for each of the variables used in this study. The dependent variables included three measures of efficiency: LOS, operating costs per adjusted patient days (costs), and FTE RN staffing per bed. ${ }^{11,48,49}$ Adjusted patient days controlled for outpatient activities, as operating costs include hospitals' outpatient activities. Operating costs were also adjusted for inflation. FTE RNs were calculated by adding full time RNs plus 0.5

Table I Listing, definition, and data source of all variables used in the analysis

\begin{tabular}{|c|c|c|}
\hline Variables & Definition & Data source \\
\hline \multicolumn{3}{|l|}{ Dependent variables } \\
\hline Length of stay & Total inpatient days divided by total discharges & CMS cost reports \\
\hline $\begin{array}{l}\text { Operating costs } \\
\text { per inpatient day }\end{array}$ & Total operating expense divided by adjusted inpatient days & CMS cost reports \\
\hline FTE RNs per bed & Total number of FTE RNs divided by total number of staffed beds & AHA Annual Survey \\
\hline \multicolumn{3}{|l|}{ Independent variable } \\
\hline $\begin{array}{l}\text { Hospitalist staffing } \\
\text { intensity }\end{array}$ & $\begin{array}{l}\text { Categorical variable: no hospitalists, low, medium, and high number of FTE } \\
\text { hospitalists; low hospitalist staffing intensity represented the lowest quartile } \\
\text { of FTE hospitalists per 1,000 adjusted patient days, high represented } \\
\text { the highest quartile, and medium represented the two quartiles in between }\end{array}$ & AHA Annual Survey \\
\hline \multicolumn{3}{|l|}{ Control variables } \\
\hline Occupancy rate & $\begin{array}{l}\text { Total inpatient days divided by (total number of staffed } \\
\text { beds multiplied by } 365 \text { ) }\end{array}$ & AHA Annual Survey \\
\hline $\mathrm{CMI}$ & $\begin{array}{l}\text { Hospitals' CMI represents the average diagnosis-related group (DRG) relative } \\
\text { weight for each given hospital; the CMI is obtained by summing the DRG } \\
\text { weights for all Medicare discharges and dividing by the number of discharges; } \\
\text { this index is obtained using both transfer-adjusted and unadjusted cases }\end{array}$ & CMS CMI files \\
\hline $\begin{array}{l}\text { Proportion of } \\
\text { Medicare patients }\end{array}$ & Total Medicare inpatient days divided by total inpatient days & AHA Annual Survey \\
\hline $\begin{array}{l}\text { Proportion of } \\
\text { Medicaid patients }\end{array}$ & Total Medicaid inpatient days divided by total inpatient days & AHA Annual Survey \\
\hline Nurse staffing intensity & Total number of FTE nurses divided by total inpatient days multiplied by 100 & AHA Annual Survey \\
\hline Market competition & $\begin{array}{l}\text { Measured using the Hirschman-Herfindahl Index }(\mathrm{HHI}) ; \mathrm{HHI} \text { values ranged } \\
\text { from } 0 \text { to I, I indicating monopolistic markets and values close to } 0 \\
\text { indicating highly competitive markets; the } \mathrm{HHI} \text { was calculated as the sum of } \\
\text { squares of individual hospital's market share at the health service area (HSA) }\end{array}$ & AHA Annual Survey \\
\hline $\begin{array}{l}\text { Medicare managed } \\
\text { care penetration }\end{array}$ & $\begin{array}{l}\text { The ratio of Medicare managed care enrollees over Medicare eligibles } \\
\text { multiplied by } 100\end{array}$ & AHRF \\
\hline Per-capita income & $\begin{array}{l}\text { Per-capita income is the total personal income of the residents of a given } \\
\text { county divided by the resident population of the county }\end{array}$ & AHRF \\
\hline $\begin{array}{l}\text { Supply of physicians } \\
\text { per } 1,000\end{array}$ & $\begin{array}{l}\text { Total number of active physicians divided by total population in county } \\
\text { multiplied by } 1,000\end{array}$ & AHRF \\
\hline
\end{tabular}

Abbreviations: CMS, Centers for Medicare and Medicaid Services; FTE, full-time equivalent; RNs, registered nurses; AHA, American Hospital Association; CMI, case-mix index; AHRF, Area Health Resource File. 
of part-time RNs. LOS (interquartile range 1.5) and operating costs (interquartile range US $\$ 1,196$ ) were log-transformed to reduce skewness.

The independent variable is a categorical measure of hospitalists' staffing intensity, operationalized as: no hospitalists, and low, medium, and high number of FTE hospitalists per 1,000 adjusted patient days. Low hospitalist staff intensity represented the lowest quartile of FTE hospitalists per 1,000 adjusted patient days (0.0003-0.04); high represented the highest quartile (0.13-24.06), and medium represented the two quartiles in between $(0.05-0.12)$. This analysis controlled for organizational and market factors that have been associated with efficiency. ${ }^{50-52}$ Organizational factors included occupancy rate, CMI, proportion of Medicare and Medicaid patients, and nurse staffing intensity. Market factors consisted of market competition, as measured by the Hirschman-Herfindahl Index, accounting for same-system hospitals in a given market, Medicare managed care penetration, per-capita income, and supply of physicians per 1,000 population. Given the fixed-effect regression model, which controls for observed and unobserved time-invariant factors, we did not include size, teaching status, for-profit status, or rural location as control variables, since these variables were relatively fixed during the study period.

\section{Analysis}

An analysis of variance was performed to compare organizational and market characteristics of hospitals in the different hospitalist staffing-intensity categories. Given the continuous nature of the dependent variables, the data were modeled using a panel regression with hospital and year-fixed effects. Facility-fixed effect was used to control for unmeasured time-invariant differences in efficiency at the hospital, market, or state level. This model accounts for how the change in the use of hospitalists impacts efficiency over time. The fixed-effect model assumes that there has been change in both the dependent and the independent variable over time. This assumption was tested a priori, and we found enough variation over time in the use of hospitalists by hospitals in our sample. There were $18.38 \%$ of hospitals in our sample that used hospitalists in 2007 and $37.34 \%$ in 2010 , thus justifying the use of a fixed-effect model. The year-fixed effect was used to adjust for time trends that may have affected hospitals' efficiency.

Three separate fixed-effect regression models were used for each of the three dependent variables: LOS, operating costs per inpatient day, and RN FTEs per bed. Hospitalist staffing intensity was the main predictor: no hospitalists, and low, medium, and high number of FTE hospitalists per 1,000 adjusted patient days. All analyses were conducted in SAS version 9.3 and Stata version 13.

\section{Results}

The analysis of variance and frequencies for the different levels of hospitalist staffing intensity (Table 2) revealed that on average hospitals that did not use hospitalists had the highest LOS (8.2). Results indicate that the higher the hospitalist staffing intensity, the lower the LOS (4.8-4.4). Hospitals that did not use hospitalists had the lowest costs $(\$ 1,633)$, RN staffing per bed (1.2), occupancy rate (51\%), and CMI (1.3), and were located in markets with the lowest competition (0.8), Medicare managed care penetration $(18.1 \%)$, per-capita income $(\$ 33,803)$, and supply of physicians per 1,000 population (1.6). Higher hospitalist staffing intensity was associated with higher costs $(\$ 1,808.84-\$ 2,535)$, RN staffing per bed (1.5-1.8), and the proportion of Medicare patients (46.1\%-53.7\%). Higher hospitalist staffing intensity was also associated with a lower supply of physicians per 1,000 population (2.9-2.5) in the market, lower proportion of Medicaid patients (23.4\%-14.2\%), and lower occupancy rate $(65.4 \%-55.4 \%)$.

Our fixed-effect regression analysis (Table 3) showed that changing from no hospitalist use to high hospitalist-staffing intensity was associated with lower $\operatorname{LOS}(P<0.05)$, but also higher operating costs $(P<0.05)$ and RN staffing per bed $(P<0.05)$. Our findings also showed that changing from no hospitalist use to low and medium hospitalist-staffing intensity was not significantly associated with any of the efficiency indicators. This provided partial support for our hypotheses: $\mathrm{H}_{1}$ was supported, while $\mathrm{H}_{2}$ and $\mathrm{H}_{3}$ were not.

Additionally, we found that an increase in occupancy rate was associated with an increase in $\operatorname{LOS}(P<0.01)$ and RN staffing $(P<0.001)$ and a reduction in costs $(P<0.001)$. An increase in the proportion of Medicare patients was associated with increased costs $(P<0.001)$ and RN staffing $(P<0.01)$. Finally, the results showed that an increase in the proportion of Medicaid patients was associated with reduced costs $(P<0.05)$ and RN staffing $(P<0.05)$.

\section{Discussion}

This study used agency theory to explore the relationship between hospital use of hospitalists, particularly hospitalist staffing intensity and hospital efficiency, as measured by LOS, costs, and RN staffing per bed. Our findings provide support for our first hypothesis $\left(\mathrm{H}_{1}\right)$, showing increased hospitalist staffing intensity to be associated with lower LOS. 


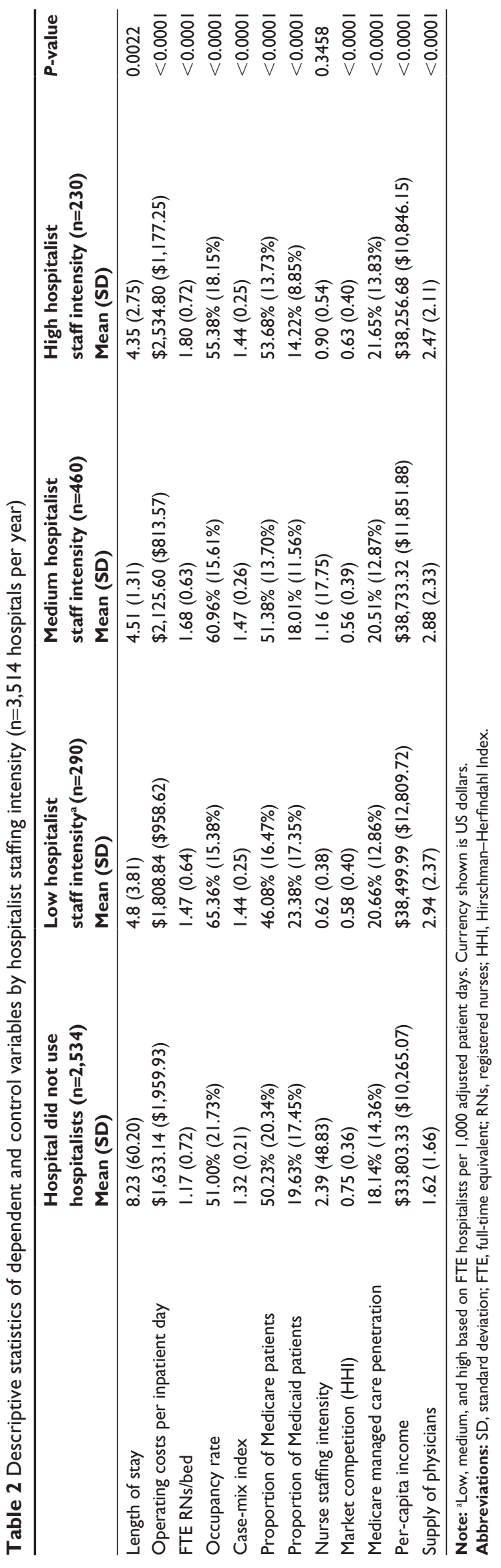

Table 3 Fixed-effect regression analysis of hospitalist staffing intensity and length of stay, costs, and RN staffing per bed ( $n=3,5$ । 4 hospitals per year)

\begin{tabular}{|c|c|c|c|}
\hline & $\begin{array}{l}\text { Length } \\
\text { of stay } \\
\beta \text { (SE) }\end{array}$ & $\begin{array}{l}\text { Operating costs } \\
\text { per inpatient day } \\
\beta \text { (SE) }\end{array}$ & $\begin{array}{l}\text { FTE } \\
\text { RNs/bed } \\
\beta \text { (SE) }\end{array}$ \\
\hline \multicolumn{4}{|c|}{ Independent variables } \\
\hline \multicolumn{4}{|c|}{ Hospitalist staffing intensity } \\
\hline Low & $\begin{array}{l}-0.014 \\
(0.10)\end{array}$ & $\begin{array}{l}-0.003 \\
(0.021)\end{array}$ & $\begin{array}{l}-0.009 \\
(0.022)\end{array}$ \\
\hline Medium & $\begin{array}{l}-0.016 \\
(0.10)\end{array}$ & $\begin{array}{l}0.018 \\
(0.022)\end{array}$ & $\begin{array}{l}0.024 \\
(0.023)\end{array}$ \\
\hline High & $\begin{array}{l}-0.024^{*} \\
(0.012)\end{array}$ & $\begin{array}{l}0.066^{*} \\
(0.028)\end{array}$ & $\begin{array}{l}0.08 I^{*} \\
(0.034)\end{array}$ \\
\hline \multicolumn{4}{|l|}{ Control variables } \\
\hline Occupancy rate & $\begin{array}{l}0.002 * * \\
(0.001)\end{array}$ & $\begin{array}{l}-0.011 * * * \\
(0.003)\end{array}$ & $\begin{array}{l}0.009 * * * \\
(0.002)\end{array}$ \\
\hline Case-mix index & $\begin{array}{l}0.091 \\
(0.049)\end{array}$ & $\begin{array}{l}-0.088 \\
(0.225)\end{array}$ & $\begin{array}{l}0.085 \\
(0.088)\end{array}$ \\
\hline $\begin{array}{l}\text { Proportion of } \\
\text { Medicare patients }\end{array}$ & $\begin{array}{l}-0.001 \\
(0.001)\end{array}$ & $\begin{array}{l}0.004 * * * \\
(0.001)\end{array}$ & $\begin{array}{l}0.002 * * \\
(0.001)\end{array}$ \\
\hline $\begin{array}{l}\text { Proportion of } \\
\text { Medicaid patients }\end{array}$ & $\begin{array}{l}-0.001 \\
(0.001)\end{array}$ & $\begin{array}{l}-0.003^{*} \\
(0.002)\end{array}$ & $\begin{array}{l}-0.003 * \\
(0.001)\end{array}$ \\
\hline $\begin{array}{l}\text { Nurse staffing } \\
\text { intensity }\end{array}$ & $\begin{array}{l}-0.001 \\
(0.001)\end{array}$ & $\begin{array}{l}0.001 \\
(0.001)\end{array}$ & $\begin{array}{l}0.001 \\
(0.001)\end{array}$ \\
\hline $\begin{array}{l}\text { Market competition } \\
(\mathrm{HHI})\end{array}$ & $\begin{array}{l}0.073 \\
(0.039)\end{array}$ & $\begin{array}{l}-0.004 \\
(0.058)\end{array}$ & $\begin{array}{l}-0.026 \\
(0.07 I)\end{array}$ \\
\hline $\begin{array}{l}\text { Medicare managed } \\
\text { care penetration }\end{array}$ & $\begin{array}{l}-0.001 \\
(0.001)\end{array}$ & $\begin{array}{l}-0.002 \\
(0.003)\end{array}$ & $\begin{array}{l}-0.001 \\
(0.002)\end{array}$ \\
\hline Per-capita income & $\begin{array}{l}0.003 \\
(0.002)\end{array}$ & $\begin{array}{l}0.003 \\
(0.002)\end{array}$ & $\begin{array}{l}0.001 \\
(0.003)\end{array}$ \\
\hline Supply of physicians & $\begin{array}{l}0.016 \\
(0.012)\end{array}$ & $\begin{array}{l}0.013 \\
(0.015)\end{array}$ & $\begin{array}{l}-0.020 \\
(0.024)\end{array}$ \\
\hline
\end{tabular}

Notes: $* P \leq 0.05$; $* * P \leq 0.01$ I;**P $<0.00$ I; ${ }^{a}$ reference group for hospitalist staffing intensity is hospitalists did not provide care; "low, medium, and high based on FTE hospitalists per I,000 adjusted patient days.

Abbreviations: SE, standard error; FTE, full-time equivalent; RNs, registered nurses; $\mathrm{HH}$, Hirschman-Herfindahl Index.

However, high hospitalist staffing intensity was also associated with increased costs per inpatient day and RN staffing per bed, which were contrary to our last two hypotheses $\left(\mathrm{H}_{2}\right.$ and $\mathrm{H}_{3}$ ).

Our findings suggest a nonlinear relationship between hospitalist staffing intensity and LOS. High hospitalist staffing intensity was associated with lower LOS. This suggests that simply using hospitalists may not achieve the desired outcome. Appropriate hospitalist staffing levels matter. Our findings suggest that high levels of hospitalists can lower LOS. This may be a result of reduced hospitalist workload and increased patient oversight. ${ }^{53}$ Although low and medium hospitalist staffing intensity was associated with lower LOS, this relationship was not statistically significant. Our findings are consistent with prior studies that found hospitalists to reduce LOS. ${ }^{9-13}$ However, our findings contribute to the 
extant literature by revealing that hospitalist staffing intensity matters as it pertains to reducing LOS.

High levels of hospitalist staffing intensity were associated with higher costs and RN staffing per bed. This may be explained by the concomitant increased use of RN FTEs per bed for hospitals with high hospitalist intensity. Furthermore, these hospitals have additional staffing costs as a result of the hiring and contracting of additional hospitalists. Therefore, while a high hospitalist staffing intensity may be associated with lower LOS, the impact of lower LOS on costs may be offset by the increased RN and hospitalist staffing costs. To what extent these higher costs may impact the hospital bottom line will depend on the impact of increased hospitalist staffing intensity on revenues. The increased costs may be more than offset by increased revenues, if these hospitals are able to attract privately insured patients by differentiating themselves from their competitors based on staff quality. Our finding on costs was contrary to prior studies, which have found hospitalists to reduce costs. ${ }^{9-12}$ However, prior studies were generally limited in scope (single hospital) and settings (pediatrics or teaching). Additionally, prior studies in the exploration of the relationship between hospitalists and costs did not consider staffing intensity. Further research is needed to examine the relationship between hospitalist staffing intensity and financial performance.

A sensitivity analysis was conducted to explore if the effect of hospitalist staffing intensity on efficiency varied based on teaching status. These results revealed no association between hospitalist staffing intensity and efficiency among teaching hospitals. However, the sensitivity-analysis results for non-teaching hospitals were similar to those reported in Table 3. Given our fixed-effect model, most of the teaching hospitals were dropped from the analysis, since these hospitals were early adopters of hospitalists and may not have experienced much change in hospitalist staffing patterns during the study period. ${ }^{54}$ This reduced the statistical power to detect the effect of differences in hospitalist staff intensity among teaching hospitals.

Results of our covariates indicate that an increase in occupancy rate is associated with increased LOS and RN staffing per bed and lower operating costs. The increased RN staffing per bed may be explained by the increased workload associated with an increased occupancy rate. The increased LOS associated with increased occupancy may be explained by inadequate staffing, which may in turn result in lower quality of care and increased LOS. ${ }^{55-58}$ On the other hand, the lower operating costs associated with increased occupancy may be the result of economies of scale.
Our study also found an increase in the proportion of Medicare patients to be associated with higher operating costs and RN staffing. This may be explained by the greater acuity of Medicare patients, which in turn will require more clinical personnel and can result in increased costs. The reduced costs and RN staffing associated with increased Medicaid patients may be a result of hospitals with higher Medicaid population not having the necessary resources and being forced to put in place cost-containment strategies.

There are several limitations to our study. First, our study was restricted to the use of secondary data and self-reported staffing data. However, the data sets used in this analysis are widely accepted and used in the hospital literature. Second, we did not examine the potential moderating effect of covariates on the relationship between hospitalist staffing intensity and efficiency. For example, the effect of hospitalist staffing intensity on efficiency may vary based on differences in the CMI. Future studies should explore these relationships. Third, this study was limited to how hospitalists impact efficiency. Future studies should examine the effect of hospitalist use on other aspects of hospital performance, such as quality, financial performance, and patient experience. Finally, this study included data aggregated at the hospital level. Future research is needed using multilevel models to account for the effect of patient-, hospitalist-, and hospital-level factors.

\section{Conclusion}

Our study explored the relationship between hospitalist staffing intensity and hospitals' efficiency. Our results clearly indicate that while the use of hospitalists can help reduce LOS, it comes at the price of higher costs and RN staffing needs. These findings may indicate that this staffing strategy may be generally adopted by hospitals with slack resources that can afford the costs associated with the use of hospitalists.

\section{Recommendation}

Our findings reveal the difficult choices hospital managerial teams may be facing. While low hospitalist staff intensity does not seem to have an impact on efficiency, high hospitalist staffing intensity can lower LOS but at increased costs and RN staffing. Further research is needed to examine the organizational factors that may explain why hospitals with high hospitalist staffing intensity experience higher costs per inpatient day and higher RN staffing per bed despite having lower LOS.

Given the unprecedented growth of the use of hospitalists, hospital managerial teams should be clear on the goal they 
intend to achieve. With the increasing debate on improving the quality of care delivered in US hospitals, particularly with respect to hospital-acquired conditions, hospitalists may serve as an innovative strategy, given their potential to reduce LOS. As hospitals reduce LOS and discharge patients sooner, this may reduce patients' risk of hospital-acquired conditions.

\section{Disclosure}

The authors report no conflicts of interest in this work.

\section{References}

1. Society of Hospital Medicine. Society of Hospital Medicine general information. 2012. Available from: http://www.hospitalmedicine.org/ Content/NavigationMenu/AboutSHM/GeneralInformation/General_ Information.htm. Accessed February 26, 2012.

2. Wachter RM, Goldman L. The emerging role of "hospitalists" in the American health care system. $N$ Engl J Med. 1996;335(7):514-517.

3. Freeman WD, Gronseth G, Eidelman BH. Invited article: Is it time for neurohospitalists? Neurology. 2008;70(15):1282-1288.

4. Hoff TH, Whitcomb WF, Williams K, Nelson JR, Cheesman RA. Characteristics and work experiences of hospitalists in the United States. Arch Intern Med. 2001;161(6):851-858.

5. Schoeppner HL, Miller SL. Developing a gastroenterology hospitalist service. Gastrointest Endosc Clin N Am. 2006;16(4):743-750.

6. Greeno R. Hospitals embrace hospitalist concept to streamline patient flow, reduce costs. Managed Healthcare Executive. 2006:38-39.

7. American Hospital Association. AHA Annual Survey Database ${ }^{\mathrm{TM}}$ fiscal year 2012. 2014. Available from: http://www.ahadataviewer. com/book-cd-products/AHA-Survey. Accessed May 28, 2014.

8. VanLare JM, Conway PH. Value-based purchasing - national programs to move from volume to value. $N$ Engl J Med. 2012;367(4):292-295.

9. Baudendistel TE, Wachter RM. The evolution of the hospitalist movement in the USA. Clin Med. 2002;2(4):327-330.

10. Coffman J, Rundall TG. The impact of hospitalists on the cost and quality of inpatient care in the United States: a research synthesis. Med Care Res Rev. 2005;62(4):379-406.

11. Peterson MC. A systematic review of outcomes and quality measures in adult patients cared for by hospitalists vs nonhospitalists. Mayo Clin Proc. 2009;84(3):248-254.

12. Wachter RM, Goldman L. The hospitalist movement 5 years later. JAMA. 2002;287(4):487-494.

13. Rachoin JS, Skaf J, Cerceo E, et al. The impact of hospitalists on length of stay and costs: systematic review and meta-analysis. Am J Manag Care. 2012;18(1):e23-e30.

14. Cox JA, Bernard AC, Bottiggi AJ, et al. Influence of in-house attending presence on trauma outcomes and hospital efficiency. J Am Coll Surg. 2014;218(4):734-738.

15. Douglas VC, Scott BJ, Berg G, Freeman WD, Josephson SA. Effect of a neurohospitalist service on outcomes at an academic medical center. Neurology. 2012;79(10):988-994.

16. Carek PJ, Boggan H, Mainous AG 3rd, Geesey ME, Dickerson L, Laird S. Inpatient care in a community hospital: comparing length of stay and costs among teaching, hospitalist, and community services. Fam Med. 2008;40(2):119-124.

17. Davis KM, Koch KE, Harvey JK, Wilson R, Englert J, Gerard PD. Effects of hospitalists on cost, outcomes, and patient satisfaction in a rural health system. Am J Med. 2000;108(8):621-626.

18. Everett G, Uddin N, Rudloff B. Comparison of hospital costs and length of stay for community internists, hospitalists, and academicians. $J$ Gen Intern Med. 2007;22(5):662-667.

19. Hackner D, Tu G, Braunstein GD, Ault M, Weingarten S, Mohsenifar Z. The value of a hospitalist service: efficient care for the aging population? Chest. 2001;119(2):580-589.
20. Halpert AP, Pearson SD, LeWine HE, McKean SC. The impact of an inpatient physician program on quality, utilization, and satisfaction. $\mathrm{Am}$ J Manag Care. 2000;6(5):549-555.

21. Kearns PJ, Wang CC, Morris WJ, et al. Hospital care by hospital-based and clinic-based faculty: a prospective, controlled trial. Arch Intern Med. 2001;161(2):235-241.

22. Palmer HC, Armistead NS, Elnicki DM, et al. The effect of a hospitalist service with nurse discharge planner on patient care in an academic teaching hospital. Am J Med. 2001;111(8):627-632.

23. Tingle LE, Lambert CT. Comparison of a family practice teaching service and a hospitalist model: costs, charges, length of stay, and mortality. Fam Med. 2001;33(7):511-515.

24. Chen LM, Birkmeyer JD, Saint S, Jha AK. Hospitalist staffing and patient satisfaction in the national Medicare population. J Hosp Med. 2013;8(3):126-131.

25. Craig DE, Hartka L, Likosky WH, Caplan WM, Litsky P, Smithey J. Implementation of a hospitalist system in a large health maintenance organization: the Kaiser Permanente experience. Ann Intern Med. 1999;130(4 Pt 2):355-359.

26. Kroger E, Grant M. Are hospitalists truly more efficient? A natural experiment. J Gen Intern Med. 1998;13:S66.

27. Ross SA. The economic theory of agency: the principal's problem. $A m$ Econ Rev. 1973;63(2):134-139.

28. Berenson RA, Ginsburg PB, May JH. Hospital-physicians relations: cooperation, competition, or separation? Health Aff (Millwood). 2007;26(1):w31-w43.

29. Pauly M, Redisch M. The not-for-profit hospital as a physicians' cooperative. Am Econ Rev. 1973;63(1):87-99.

30. Burns LR, Andersen RM, Shortell SM. The effect of hospital control strategies on physician satisfaction and physician-hospital conflict. Health Serv Res. 1990;25(3):527-560.

31. Goes JB, Zhan C. The effects of hospital-physician integration strategies on hospital financial performance. Health Serv Res. 1995;30(4):507-530.

32. Noy S, Lachman R. Physician hospital conflict among salaried physicians. Health Care Manage Rev. 1993;18(4):60-69.

33. Brennan TA, Rothman DJ, Blank L, et al. Health industry practices that create conflicts of interest: a policy proposal for academic medical centers. JAMA. 2006;295(4):429-433.

34. Rodwin MA. Medicine, Money, and Morals: Physicians' Conflicts of Interest. New York: Oxford University Press; 1993.

35. Thompson DF. Understanding financial conflicts of interest. $N$ Engl J Med. 1993;329(8):573-576.

36. Collier VU. Use of pay for performance in a community hospital private hospitalist group: a preliminary report. Trans Am Clin Climatol Assoc. 2007;118:263-272.

37. Lundberg S, Balingit P, Wali S, Cope D. Cost-effectiveness of a hospitalist service in a public teaching hospital. Acad Med. 2010;85(8): 1312-1315.

38. Pham HH, Devers KJ, Kuo S, Berenson R. Health care market trends and the evolution of hospitalist use and roles. J Gen Intern Med. 2005;20(2):101-107.

39. Wachter RM. An introduction to the hospitalist model. Ann Intern Med. 1999;130(4 Pt 2):338-342.

40. Eisenhardt KM. Agency theory: an assessment and review. Acad Manage Rev. 1989;14(1):57-74.

41. Casalino LP, November EA, Berenson RA, Pham HH. Hospital-physician relations: two tracks and the decline of the voluntary medical staff model. Health Aff (Millwood). 2008;27(5):1305-1314.

42. Runy LA. Why the hospital-physician staffing structure must change. Hosp Health Netw. 2009;83(6):55-56.

43. Wachter RM, Whitcomb WF, Nelson JR. Financial implications of implementing a hospitalist program. Healthc Financ Manage. 1999; 53(3):48-51.

44. Casey MM, Hung P, Moscovice I, Prasad S. The use of hospitalists by small rural hospitals results of a national survey. Med Care Res Rev. 2014;71(4):356-366. 
45. American Hospital Association. AHAAnnual Survey Database ${ }^{\mathrm{TM}}$ Fiscal Year 2013. Available from: http://www.ahadataviewer.com/book-cdproducts/AHA-Survey/. Accessed November 13, 2013.

46. US Department of Health and Human Services. Health Resources and Services Administration. Area Health Resources Files (AHRF). Available from: http://www.arf.hrsa.gov/overview.htm. November 13, 2013.

47. Centers for Medicare and Medicaid Services. Cost reports. 2010. Available from: https://www.cms.gov/Research-Statistics-Dataand-Systems/Files-for-Order/CostReports/index.html?redirect=/ CostReports. Accessed November 8, 2010.

48. Vélez-González H, Pradhan R, Weech-Maldonado R. The role of non-financial performance measures in predicting hospital financial performance: the case of for-profit system hospitals. $J$ Health Care Finance. 2010;38(2):12-23.

49. Watkins AL. Hospital financial ratio classification patterns revisited: upon considering nonfinancial information. J Account Public Policy. 2000;19(1):73-95.

50. Bazzoli GJ, Fareed N, Waters TM. Hospital financial performance in the recent recession and implications for institutions that remain financially weak. Health Aff (Millwood). 2014;33(5):739-745.

51. Bazzoli GJ, Chan B, Shortell SM, D’Aunno T. The financial performance of hospitals belonging to health networks and systems. Inquiry. 1999;37(3):234-252.
52. Zhao M, Bazzoli GJ, Clement JP, Lindrooth RC, Nolin JA, Chukmaitov AS. Hospital staffing decisions: does financial performance matter? Inquiry. 2008;45(3):293-307.

53. Elliott DJ, Young RS, Brice J, Aguiar R, Kolm P. Effect of hospitalist workload on the quality and efficiency of care. JAMA Intern Med. 2014;174(5):786-793.

54. Epané JP. Hospitalists and organizational performance [unpublished doctoral dissertation]. Health Services Administration, University of Alabama at Birmingham: Birmingham (AL); 2013.

55. Weissman JS, Rothschild JM, Bendavid E, et al. Hospital workload and adverse events. Med Care. 2007;45(5):448-455.

56. Kane RL, Shamliyan TA, Mueller C, Duval S, Wilt TJ. The association of registered nurse staffing levels and patient outcomes: systematic review and meta-analysis. Med Care. 2007;45(12):1195-1204.

57. Lichtig LK, Knauf RA, Milholland DK. Some impacts of nursing on acute care hospital outcomes. J Nurs Adm. 1999;29(2):25-33.

58. Weissman JS, López L, Schneider EC, Epstein AM, Lipsitz S, Weingart SN. The association of hospital quality ratings with adverse events. Int $J$ Qual Health Care. 2014;26(2):129-135.
Innovation and Entrepreneurship in Health

\section{Publish your work in this journal}

Innovation and Entrepreneurship in Health is an international, peer reviewed, open access journal publishing original research, reports, reviews and commentaries on innovation and entrepreneurship in health. Special focus will be given to the theory, process, and practice of innovation and entrepreneurship by individuals and organizations

\section{Dovepress}

within the health care context globally. The manuscript management system is completely online and includes a very quick and fair peer review system, which is all easy to use. Visit http://www.dovepress.com/ testimonials.php to read real quotes from published authors.

Submit your manuscript here: http://www.dovepress.com/innovation-and-entrepreneurship-in-health-journal 